\title{
Assessing disparities in the urban-rural service: a case of public bus services in Peninsular Malaysia
}

\begin{abstract}
An understanding of bus service disparities between urban and rural settlements is necessary to provide the best approach to improving and providing an efficient public transportation system in the country. An efficient public transportation system will contribute towards sustainable economic growth and healthy social development of the district, which, in turn, will ensure human security in respect of the mobility of goods and services for today's and future needs. However, limited studies that analyse theservice gap and local demand for the public bus service in Peninsular Malaysia have been conducted. The improvement in bus service reliability depends on several parameters including the route coverage and schedule. This study presents an empirical analysis of the fixed-route hour level of service (LOS) for urban and rural bus services to understand the level of reliability and quality of the service provided. A field survey was conducted to collect the secondary data concerning the bus routes and schedules from the local bus operators. Through a sampling survey of bus lines in selected urban and rural settlements in Peninsular Malaysia, service reliability based on the fixed-route hour service is evaluated. A total of nine (9) bus companies with a total of 48 routes were selected to represent nine (9) bus terminals operating in Johor, Penang, Pahang and Perak. Johor represents the southern states, while Penang represents the northern states. For the east-coast states, Pahang is selected, while Perak represents a still developing state, which is yet to reach the advanced level of large conurbations. The distance of a bus route from the origin to the destination is also analysed. A standard service quality measure is referred to in determining the level of service (LOS) and for identifying the service disparities between urban and rural settlements. The results indicate that the LOS for the fixed-route hour of bus services in the rural areas range from $\mathrm{C}$ to $\mathrm{D}$ and $\mathrm{B}$ to $\mathrm{E}$ in the urban settlement. The recommendations put forward include the improvement of real-time scheduling of buses, expansion of service hours and revised fare systems to ensure the future sustainability of the urban and rural bus services in Malaysia.
\end{abstract}

Keyword: Urban; Rural; Public transport; Level-of-service 